\title{
OPEN Using machine learning methods for supporting GR2M model in runoff estimation in an ungauged basin
}

\author{
Pakorn Ditthakit ${ }^{1,3 凶}$, Sirimon Pinthong ${ }^{1,3}$, Nureehan Salaeh ${ }^{1,3}$, Fadilah Binnui ${ }^{1,3}$, \\ Laksanara Khwanchum ${ }^{2,3}$ \& Quoc Bao Pham ${ }^{4 凶}$
}

Estimating monthly runoff variation, especially in ungauged basins, is inevitable for water resource planning and management. The present study aimed to evaluate the regionalization methods for determining regional parameters of the rainfall-runoff model (i.e., GR2M model). Two regionalization methods (i.e., regression-based methods and distance-based methods) were investigated in this study. Three regression-based methods were selected including Multiple Linear Regression (MLR), Random Forest (RF), and M5 Model Tree (M5), and two distance-based methods included Spatial Proximity Approach and Physical Similarity Approach (PSA). Hydrological data and the basin's physical attributes were analyzed from 37 runoff stations in Thailand's southern basin. The results showed that using hydrological data for estimating the GR2M model parameters is better than using the basin's physical attributes. RF had the most accuracy in estimating regional GR2M model's parameters by giving the lowest error, followed by M5, MLR, SPA, and PSA. Such regional parameters were then applied in estimating monthly runoff using the GR2M model. Then, their performance was evaluated using three performance criteria, i.e., Nash-Sutcliffe Efficiency (NSE), Correlation Coefficient ( $r$ ), and Overall Index (OI). The regionalized monthly runoff with RF performed the best, followed by SPA, M5, MLR, and PSA. The Taylor diagram was also used to graphically evaluate the obtained results, which indicated that RF provided the products closest to GR2M's results, followed by SPA, M5, PSA, and MLR. Our finding revealed the applicability of machine learning for estimating monthly runoff in the ungauged basins. However, the SPA would be recommended in areas where lacking the basin's physical attributes and hydrological information.

Precisely estimating hydrological parameters in the ungauged basin has drawn the attention of hydrologists and water resources engineering ${ }^{1}$. In meteorology, the assessment of runoff is extremely important ${ }^{2}$, especially in areas where there is no measuring station that cannot be calibrated. Therefore, the regionalization method is optional for transferring model parameters from the gauged basin to the ungauged basin ${ }^{3,4}$. The popular regionalization methods are physical similarity, spatial proximity, and regression ${ }^{5}$. Previously, many studies have been conducted and compared the performance of the regionalization methods to predict total streamflow or direct runoff ${ }^{6}$ in the ungauged catchment with various hydrological models (WASMOD ${ }^{7}, \mathrm{VIC}^{8}, \mathrm{SWAT}^{9}, \mathrm{GR}^{2} \mathrm{~J}^{10}$, HMETS $^{10}$, MOHYSE ${ }^{10}$, and HEC-HMS ${ }^{11}$ ) for different regions. Some of them showed that distance-based (spatial proximity, physical similarity) outperformed regression methods ${ }^{7,8}$. The combined watershed classification of inverse distance weighted (IDW) and physical similarity methods was investigated to predict streamflow in the ungauged catchment by Kanishka and Eldho ${ }^{9}$. Swain and Patra ${ }^{3}$ pointed that the spatial proximity between the gauged catchment and the ungauged catchment gave better results than the physical similarity for predicting the continuous streamflow. Arsenault et al. ${ }^{10}$ studied the efficacy of three regionalization methods: multiple linear regression (MLR), spatial proximity, and physical similarity, to predict current flow in ungauged catchments of Mexico. They showed that transferring a set of parameters from a nearby reservoir is the most efficient method

\footnotetext{
${ }^{1}$ School of Engineering and Technology, Walailak University, Nakhon Si Thammarat 80161, Thailand. ${ }^{2}$ School of Languages and General Education, Walailak University, Nakhon Si Thammarat 80161, Thailand. ${ }^{3}$ Center of Excellence in Sustainable Disaster Management, Walailak University, Nakhon $\mathrm{Si}$ Thammarat 80161, Thailand. ${ }^{4}$ Institute of Applied Technology, Thu Dau Mot University, Thu Dau Mot City, Binh Duong Province 821389, Vietnam. ${ }^{\circledR}$ email: dpakorn@mail.wu.ac.th; phambaoquoc@tdmu.edu.vn
} 
for estimating the runoff in ungauged basins. Tegegne and $\mathrm{Kim}^{12}$ proposed a catchment runoff-response similarity (CRRS) method to identify crucial properties for supporting the hydrological similarity. This approach was conducted with South Korea's Geum River Basin (GRB) and Ethiopia's Lake Tana Basin (LTB). The results showed that CRRS performed better than the others. Koçyiğit et al. ${ }^{13}$ found that when the geometric dimensions of the sub-basin changed, the hydrological parameters of those sub-basins also changed.

Recently, machine learning has been popular and widely applied in hydrology and water resources engineering. Hussain and $\mathrm{Khan}^{14}$ indicated that random forest (RF) was more effective than multilayer perceptron (MLP) and support vector regression (SVR) for monthly flow forecasting in Hunza River, Pakistan. Schoppa et al. ${ }^{15}$ showed that random forest could simulate both small and medium floods equivalent to the HYDROMAD model. Wang and Wang ${ }^{16}$ found that multiple linear regression (MLR) and M5P model tree (M5P) gave more precisely in predicting the daily water level in Lake Erie than Gaussian process (GP), multilayer perceptron (MLP), random forest (RF), and k-nearest neighbor (KNN). For predicting the flow in ungauged basins, Araza et al. ${ }^{17}$ applied the regionalizing RF models in the 21 mountainous regions of Luzon, Philippines. However, very few researches have been conducted for applying machine learning for estimating hydrological model parameters. Recently, Saadi et al. ${ }^{18}$ explored RF algorithms' ability to express the relationship between hourly hydrological model $(\mathrm{GR} 4 \mathrm{H})$ parameters and climate/landscape catchment in the 870 catchments in the United States and 1355 catchments in France.

The GR2M model (Rural Genius model) has lately been used to simulate a watershed's hydrological features due to climate variability on hydrologic regimes ${ }^{19}$ and evaluate the effects of climate change on runoff ${ }^{20}$. It was utilized to screen hydrologic data to study hydrological response across the Lower Mekong Basin ${ }^{21}$. Boulariah et al. ${ }^{22}$ found that the GR2M model gave better performance than the ABCD. The runoff simulation under various climate conditions in the Wimmera catchment was studied using four monthly rainfall-runoff models: abcd, Budyko, GR2M, and WASMOD by Topalović et al. ${ }^{23}$. The effects of climate scenarios on monthly river runoff in the Cheliff, Tafna, and Macta in North-West ${ }^{24}$ were conducted by the GR2M model. Rintis and Setyoasri ${ }^{25}$ found that the GR2M model gave a comparable performance to Mock and NRECA methods. The GR2M model and Artificial Neural Network were utilized to reconstruct monthly river flow for Irish catchments ${ }^{26}$. The regionalized GR2M model's parameters were developed to predict monthly runoff in the ungauged basins for northern Algeria $^{27}$.

Thailand's southern region, located in the tropical climate, has been experiencing water-related disasters (e.g., flooding and drought). The comprehension of spatiotemporal hydrological characteristics, especially runoff, can reduce or alleviate extensive damage to human lives and properties and sustain economic growth ${ }^{28-31}$. As mentioned earlier, accuracy in estimating monthly runoff variation in the ungauged basin is vital for water resources planning and management. The regionalization approach has been widely accepted for this purpose. However, in Thailand, especially in the southern region, there was no research work using machine learning to estimate the regionalized GR2M parameters. To fulfill this gap in the literatures, our research aimed to investigate and compare the performance of two main regionalization approaches, i.e., regression-based and distance-based methods, to determine the GR2M model parameters for monthly runoff estimation at an ungauged basin in southern Thailand. It is the first attempt to discover the most practical approach for obtaining the regionalized GR2M parameters under the data scarcity context in the south region, Thailand. The following is an outline of how this article is structured: (1) the rationale for conducting this research work and its related literature review; (2) the study area explanation; (3) The GR2M description; (4) the framework and its detailed information of this research methodology; (5) our results, findings, and discussion; (6) this research conclusion and its contributions.

Study area. Our research work focused on three of five major river basins in the southern basin of Thailand (see Fig. 1): the Peninsula-East Coast $\left(26,024 \mathrm{~km}^{2}\right)$, Peninsula-West Coast $\left(18,841 \mathrm{~km}^{2}\right)$, and Thale Sap Songkhla $\left(8484 \mathrm{~km}^{2}\right)$ due to the available hydrological information. This peninsula area is located in between the Andaman Sea and the South China Sea. In the northern and central regions, there is a long western mountain range, and in the midst of the ridge's southern region is the Nakhon Si Thammarat ridge. The monsoon winds from the northeast and southwest are primarily responsible for its climatological characteristics. A minor coastal plain exists in the Peninsula-East Coast watershed, with short rivers of fewer than $150 \mathrm{~km}$ draining into the Gulf of Thailand. This watershed had nine runoff stations used for data analysis. The Peninsula-West Coast Watershed features short rivers that run into the Andaman Sea in the west and southwest. The runoff information was collected and analyzed from nineteen runoff stations. Thale Sap Songkhla watershed mainly locates in Songkhla, Phatthalung, and the lower part of Nakhon Si Thammarat. There were nine runoff stations available in the Thale Sap Songkhla watershed.

GR2M model. The GR2M is a conceptual monthly rainfall-runoff mathematical model developed by Demagref in the late 1980s. Later on, several versions have been continuously being improved its efficiency by Kabouya $^{32}$, Makhlouf ${ }^{33}$, Mouelhi ${ }^{34}$ until Mouelhi et al. ${ }^{35}$. This study used the version of 2006b. Literature reviews showed its performance, applicability, and simplicity compared to other model ${ }^{36}$ due to requiring two parameters: the ability to keep moisture in the soil $\left(\mathrm{X}_{1}\right)$ and the water exchange coefficient $\left(\mathrm{X}_{2}\right)$. Monthly rainfall, runoff, and evapotranspiration are the only three meteorological and hydrological data necessary ${ }^{35,37}$. Total runoff hydrograph, soil moisture content, groundwater flow, etc., are the model results. The water balance concept with two reservoirs was utilized for the GR2M model, as presented in Fig. 2. In the upper reservoir, the basin's soil moisture $(S)$ depends on production store: $\mathrm{X}_{1}(\mathrm{~mm})$. And the lower reservoir is river flow $(\mathrm{R})$, which is regulated by the exchange coefficient water: $\mathrm{X}_{2}$. and a maximum capacity of $60 \mathrm{~mm}$. Starting with precipitation penetrated the soil, soil moisture is at the level: $\mathrm{S} 1(\mathrm{~mm})$. When the soil has reached saturation, the rainfall excess occurs P1 ( $\mathrm{mm})$. Some soil moisture can decrease during that process due to evapotranspiration E, resulting in the soil 




Figure 1. The station locations of rainfall, runoff, and weather stations of the study area. (This map was created by QGIS version 3.12, which can be accessed on https://qgis.org/en/site/).

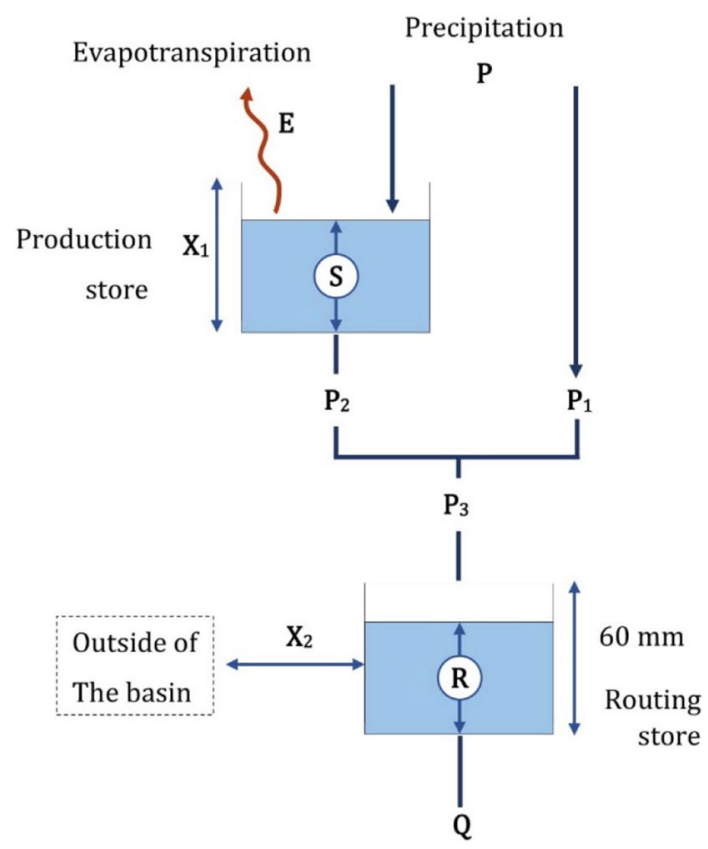

Figure 2. The GR2M model working process. Source: Adapted from Bachir et al. ${ }^{38}$, Rwasoka et al. ${ }^{39}$.

moisture remains at level: S2 $(\mathrm{mm})$. Some soil water infiltrates into the soil as subsurface water: $\mathrm{P}_{2}(\mathrm{~mm})$ and conglomerate with rainfall excess to be surface runoff: $\mathrm{P}_{3}(\mathrm{~mm})$. The surface runoff flows into the river combining with the rest water from the previous month: $\mathrm{R}(\mathrm{mm})$. The river runoff can change depending on the direction of water flowing into or out from the basin. Finally, the total runoff hydrograph is obtained. 
1) the GR2M model's calibration and verification

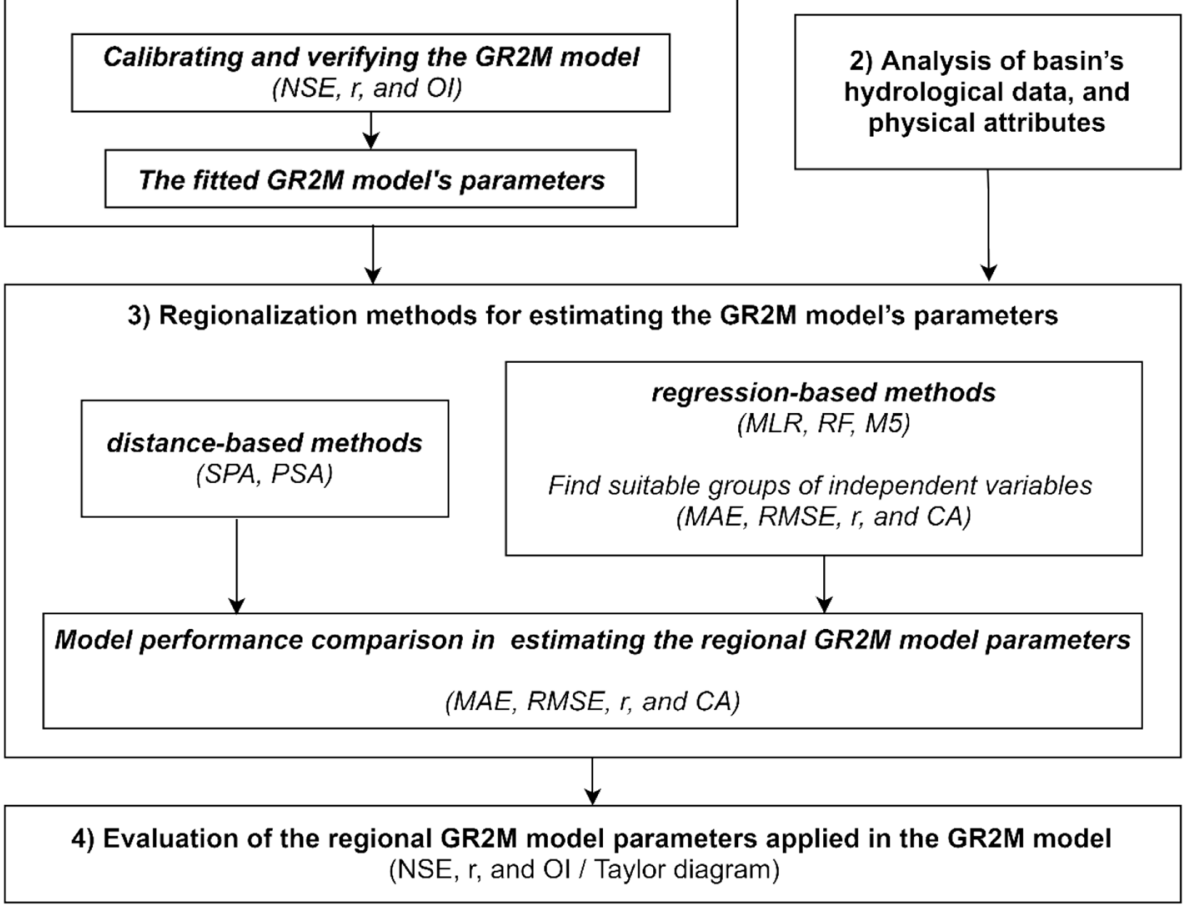

Figure 3. Framework for research methodology.

Research methodology. In this study, the research methodology (Fig. 3) consisted of four main steps, i.e., (1) the GR2M model's calibration and verification; (2) analysis of basin's hydrological data and physical attributes; (3) regionalization methods for estimating the GR2M model's parameters and their performance comparison; and (4) performance evaluation of the regional GR2M model parameters in estimating monthly runoff. The detailed information for each step can be explained as the following.

The GR2M model's calibration and verification. The model's calibration and verification were conducted to make the GR2M model reliable for estimating monthly runoff for 37 different runoff stations in the Southern Basins, Thailand. Before calibrating and verifying the GR2M model, it requires a warm-up period to determine the suitable initial values of $\mathrm{X}_{1}$ and $\mathrm{X}_{2}$ so that the model can imitate the existing hydrological characteristics of the considering basin. For doing this, the initial $\mathrm{R}$ value raining from 10 to $60 \mathrm{~mm}$ was sought. And the appropriate warm-up periods of 4 to 7 months were discovered, depending on the runoff station characteristics. In this study, the fitted values of X1 and X2 parameters for each runoff station were automatically determined with Microsoft Excel Solver's help by setting root mean square error (RMSE) as an objective function and the constraints of X1 and X2 parameters. The available monthly rainfall, evapotranspiration, and runoff data for each runoff station ranged from 41 to 80 months, resulting in the calibration and verification periods were 22 to 48 months and 10 to 39 months, respectively.

Analysis of basin's hydrological data, and physical attributes. We collected the monthly runoff (37 stations), rainfall (38 stations) and air temperature (13 stations) information from the Royal Irrigation Department (RID) and the Thai Meteorological Department (TMD). Figure 2 depicts the locations of rainfall, runoff, and weather. Areal rainfall and air temperature information for each runoff gauged station was analyzed by using Thiessen polygon. Table 1 shows the summary statistical values of hydrological data and physical characteristics of runoff gauged station used in this analysis. We used Thornthwaite ${ }^{40}$ equation to calculate monthly evapotranspiration. Figure 4 shows the physical characteristics information of the 37 runoff gauged stations, including basin area $(A)$, river length $(\mathrm{L})$, and river length from the basin's centroid to the basin outlet $\left(\mathrm{L}_{\mathrm{c}}\right)$ of runoff gauged station, were determined with the help of QGIS, a free and open-source geographic information system software. We examined the time matching to choose the appropriate times for calibrating and verifying the model. Hence, all periods for running the GR2M model were in the range of 41 to 80 months. And its calibration and verification periods were in the range of 22 to 49 months and 10 to 39 months, respectively.

Regionalization methods for estimating the GR2M model's parameters. Estimating the GR2M model's parameters in the ungauged basin was analyzed by using the regionalization concept. It is a method that transfers model parameters from donor catchments to the target station or ungauged catchments ${ }^{41}$. In this study, 


\begin{tabular}{|l|c|l|c|}
\hline Statistical value & Runoff $(\mathbf{m m})$ & Rainfall $(\mathbf{m m})$ & ET (mm) \\
\hline Hydrological data \\
\hline Maximum & 1615.43 & 1562.30 & 248.95 \\
\hline Minimum & 289.45 & 0.00 & 94.37 \\
\hline Average & 124.41 & 197.33 & 148.86 \\
\hline Standard deviation & 119.29 & 155.28 & 19.31 \\
\hline Statistical value & $\mathbf{A}\left(\mathbf{k m}^{2}\right)$ & $\mathbf{L}(\mathbf{m})$ & $\mathbf{L}_{\mathbf{c}}(\mathbf{m})$ \\
\hline Physical characteristics & 2797.96 & $141,856.48$ & $88,246.54$ \\
\hline Maximum & 12.89 & 6311.62 & 3711.12 \\
\hline Minimum & 532.70 & $45,044.77$ & $24,036.15$ \\
\hline Average & 680.71 & $36,572.41$ & $18,911.97$ \\
\hline Standard deviation
\end{tabular}

Table 1. Summary statistical values of hydrological data and physical characteristics of runoff gauged station used in this analysis.



Station code

Figure 4. Physical characteristics information of the 37 runoff gauged stations.

two regionalization methods, i.e., regression-based methods, and distance-based methods, were investigated and compared their performance.

Regression-based methods. Regression analysis was used to determine the relationship between the fitted GR2M model parameters and three basin's physical characteristics $\left(\mathrm{A}, \mathrm{L}\right.$, and $\left.\mathrm{L}_{\mathrm{c}}\right)$, and thirteen hydrological data, including monthly average areal rainfall for 12 months, and annual average areal rainfall. Each fitted GR2M model parameter (i.e., $\mathrm{X}_{1}$ and $\mathrm{X}_{2}$ ) was a dependent variable, while the basin's physical characteristics and hydrological data were independent variables. We conducted three scenarios for selecting the most suitable group of independent variables, that is, (1) using only the basin's physical characteristics, (2) using only hydrological data, and (3) combining those mentioned variables in the both scenarios 1 and 2. Three regression-based methods were selected herein, Multiple Linear Regression (MLR), Random forest (RF), and M5 Model Tree (M5). The last two methods are based on a data-driven model.

Multiple linear regression analysis (MLR).

$$
y=a_{1} x_{1}+a_{2} x_{2}+\cdots+a_{n-1} x_{n-1}+a_{n} x_{n}+b
$$

where $y$ is the dependent variable, $x_{i}$ is the independent variable; $a_{i}$ is regression coefficient, $b$ is constant of regression equation, and $\mathrm{n}$ is number of the independent variable. We utilized regression function in Microsoft excel to develop regionalized GR2M model parameter equations.

Random forest (RF). Random forest (RF) popular modification of decision trees and one of the ensemble techniques, was first introduced by Breiman in early $2001^{42}$. It can use for data classification and regression. The advantage of RF is that it can find a series of complex relationships between predictors and responses without 
any relationships between them by including decision trees ${ }^{42}$. RF creates several trees based on decision trees method, where every tree is produced by arbitrarily selecting training data set, called bagging process, and attributes (or features) from the input vector. By the voting method from the predictive output of every tree created, the model prediction is finally obtained. In regression, the tree predictor proceeds on numerical values as arbitrary to class labels used by the random forest classifier ${ }^{43}$. The most frequently used variable selection measures in tree induction are the Information Gain Ratio criterion ${ }^{44}$ and Gini index ${ }^{45}$. Unlike the M5 model tree, full-grown RF trees are not pruned. One of the key advantages of random forest regression over the M5 model tree is that it is more flexible. The speculation error always converges as the number of trees grows, even if the tree isn't pruned, and overfitting isn't a concern because of the Strong Law of Large Numbers ${ }^{43}$. We used WEKA, free and open-source software, and all default RF parameters as recommended by WEKA in our study.

M5 model tree (M5). Quinlan $1992^{44}$ irst developed the M5 model tree by employing a divide-and-conquer strategy to establish the relationship between independent and dependent variables. It can be applied to both qualitative (categorical) and quantitative variables. Building M5 involves three stages. The first stage involves the development of a decision tree by dividing the data set into subsets (or leaves). Second, to prevent an overfitted structure or weak generalizer, the overgrown tree is pruned, and linear regression functions are used to replace the pruned sub-trees. the overgrown tree is pruned and the pruned sub-trees are replaced by linear regression functions. The pruning method requires the merger of some of the lower sub-trees into one node. Finally, the smoothing process is used to compensate for the strong discontinuities that would undoubtedly exist between neighboring linear models on the trimmed trees' leaves, especially for some models with a small number of training samples. For regression-based methods, the suitable group of independent variables for determining two GR2M parameters was investigated. Thus, there were three scenarios, that is, (1) scenario-1: using only the basin's physical characteristics, (2) scenario-2: using only hydrological information, and (3) scenario-3: combining those mentioned variables in scenarios 1 and 2 .

Distance-based methods. Distance-based methods are a method for determination hydrological model parameters in the ungauged basin by transferring their values from donor catchments to the target station or ungauged catchments. Two approaches are popular recommended: Inverse Distance Weighted (IDW), and Inverse Similarity Weighted (ISW). The IDW value depends on the proximity of the distance, whereas ISW value depends on the similarity of the physical characteristics ${ }^{7}$. By applying IDW and ISW concepts, Spatial Proximity Approach ${ }^{25}$ and Physical Similarity Approach (PSA) were utilized respectively herein and can be concisely explained as follows:

Spatial proximity approach (SPA). SPA is the method to select donor stations with a proximity distance to a target station ${ }^{5}$. The distance between a gauged station (or donor station) and ungauged stations (or a target station) can be determined by:

$$
\mathrm{D}_{\mathrm{ug}}=\sqrt{\left(\mathrm{x}_{\mathrm{u}}-\mathrm{x}_{\mathrm{g}}\right)^{2}+\left(\mathrm{y}_{\mathrm{u}}-\mathrm{y}_{\mathrm{g}}\right)^{2}}
$$

where $x_{g}, x_{u}$ are the latitude (UTM), $y_{g}, y_{u}$ are the longitude (UTM); which $g$ is donor station, and $u$ is the target station, and $\mathrm{D}_{\mathrm{ug}}$ is the distance between $\mathrm{g}$ and $\mathrm{u}$ stations.

The inverse distance weighted can be calculated as:

$$
\mathrm{W}_{\mathrm{g} \_\mathrm{i}}=\frac{\left(1 / \mathrm{D}_{\mathrm{ug} \_\mathrm{i}}\right)}{\sum_{\mathrm{i}=1}^{\mathrm{n}}\left(1 / \mathrm{D}_{\mathrm{ug} \_\mathrm{i}}\right)}
$$

$\mathrm{W}_{\mathrm{g} \_\mathrm{i}}$ is the inverse distance weighted, and $\mathrm{n}$ is the total number of donor stations.

A parameter of the target station can be obtained by:

$$
\mathrm{P}_{\mathrm{ug}}=\sum_{\mathrm{i}=1}^{\mathrm{n}} \mathrm{W}_{\mathrm{g}_{\_} \mathrm{i}} \mathrm{p}_{\mathrm{g}_{-} \mathrm{i}}
$$

where $\mathrm{P}_{\mathrm{ug}}$ is the parameter of target station, and $\mathrm{p}_{\mathrm{g}_{\mathrm{i}} \mathrm{i}}$ is the parameter of donor station.

Physical similarity approach (PSA). PSA is the method based on the concept that catchments with similar physical characteristics would have similar hydrological behavior ${ }^{46}$.

$$
\mathrm{SI}_{\mathrm{ug}}=\sum_{\mathrm{i}=1}^{\mathrm{k}} \frac{\left|\mathrm{CD}_{\mathrm{g}, \mathrm{i}}-\mathrm{CD}_{\mathrm{u}, \mathrm{i}}\right|}{\Delta \mathrm{CD}_{\mathrm{gi}}}
$$

where $\mathrm{SI}_{\mathrm{ug}}$ is the similarity index, $\mathrm{CD}_{\mathrm{g}, \mathrm{i}}, \mathrm{CD}_{\mathrm{u}, \mathrm{i}}$ are the catchment descriptor of donor catchments to the target station; $\triangle \mathrm{CD}_{\mathrm{gi}}$ is the rage of ith catchment descriptor, $\mathrm{k}$ is the total number of catchment descriptor.

$$
\mathrm{W}_{\mathrm{g} \_\mathrm{i}}=\frac{\left(1 / \mathrm{SI}_{\mathrm{ug}_{\_} \mathrm{i}}\right)}{\sum_{\mathrm{i}=1}^{\mathrm{n}}\left(1 / \mathrm{SI}_{\mathrm{ug} \_\mathrm{i}}\right)}
$$


$\mathrm{W}_{\mathrm{g} \_\mathrm{i}}(\mathrm{ISW})$ is the inverse similarity weighted, and $\mathrm{n}$ is the total number of donor stations.

$$
\mathrm{P}_{\mathrm{ug}}=\sum_{\mathrm{i}=1}^{\mathrm{n}} \mathrm{W}_{\mathrm{g}_{-} \mathrm{i}} \mathrm{p}_{\mathrm{g}_{-} \mathrm{i}}
$$

where $\mathrm{P}_{\mathrm{ug}}$ is the parameter of target station, and $\mathrm{p}_{\mathrm{g}} \mathrm{i}$ is the parameter of donor station.

Model performance in estimating the regional GR2M model parameters was compared using four statistical indices, including Mean Absolute Error (MAE), Root Mean Squared Error (RMSE), Pearson Correlation Coefficient (r), and Combined Accuracy (CA $)^{47}$.

Evaluation of the regional GR2M model parameters applied in the GR2M model. Three performance criteria, including Nash-Sutcliffe Efficiency (NSE), Correlation Coefficient (r), and Overall Index (OI), and A Taylor diagram were used for evaluating the applicability of the GR2M Model. The details for each performance criteria can be delineated as the following:

Nash-Sutcliffe Efficiency (NSE) is a prominent index for determining model correctness or model performance, as shown in the following equation:

$$
\mathrm{NSE}=1-\frac{\sum_{\mathrm{i}=1}^{\mathrm{n}}\left(\mathrm{Q}_{\mathrm{cal}}-\mathrm{Q}_{\mathrm{obs}}\right)^{2}}{\sum_{\mathrm{i}=1}^{\mathrm{n}}\left(\mathrm{Q}_{\mathrm{obs}}-\overline{\mathrm{Q}}_{\mathrm{obs}}\right)^{2}}
$$

The NSE ranges from - $\alpha$ to 1 . If the NSE is near to 1, the observed and calculated runoff are likely to be identical, or it is considered the most efficient or accurate ${ }^{48}$.

The correlation coefficient ( $r$ ) shows agreement between two variables. The following equation can be used to compute the correlation coefficient between $\mathrm{X}$ and $\mathrm{Y}$.

$$
\mathrm{r}=\frac{\sum_{\mathrm{i}=1}^{\mathrm{n}}\left(\mathrm{Q}_{\mathrm{obs}}-\overline{\mathrm{Q}}_{\mathrm{obs}}\right)\left(\mathrm{Q}_{\mathrm{cal}}-\overline{\mathrm{Q}}_{\mathrm{cal}}\right)}{\sqrt{\sum_{\mathrm{i}=1}^{\mathrm{n}}\left(\mathrm{Q}_{\mathrm{obs}}-\overline{\mathrm{Q}}_{\mathrm{obs}}\right)^{2}} \cdot \sqrt{\sum_{\mathrm{i}=1}^{\mathrm{n}}\left(\mathrm{Q}_{\mathrm{cal}}-\overline{\mathrm{Q}}_{\mathrm{cal}}\right)^{2}}}
$$

The $r$-value ranges from -1 to 1 . The plus sign $(+)$ indicates the direct relation between observed and predicted values or vice versa ${ }^{49}$.

The overall index (OI) is a model performance criterion that gives the value between $-\alpha$ to 1 . The model's performance is prominent if OI approaches to $1^{50}$.

$$
\mathrm{OI}=\frac{1}{2}\left[2-\frac{\mathrm{RMSE}}{\mathrm{Q}_{\mathrm{obs}, \max }-\mathrm{Q}_{\mathrm{obs}, \min }}-\frac{\sum_{\mathrm{i}=1}^{\mathrm{n}}\left(\mathrm{Q}_{\mathrm{obs}}-\mathrm{Q}_{\mathrm{cal}}\right)^{2}}{\sum_{\mathrm{i}=1}^{\mathrm{n}}\left(\mathrm{Q}_{\mathrm{obs}}-\overline{\mathrm{Q}}_{\mathrm{obs}}\right)^{2}}\right]
$$

where $\mathrm{Q}_{\mathrm{obs}}$ is the observed runoff, $\mathrm{Q}_{\mathrm{cal}}$ is the calculated runoff, $\overline{\mathrm{Q}}_{\mathrm{obs}}$ is the average observed runoff, $\overline{\mathrm{Q}}_{\mathrm{cal}}$ is the average calculated runoff, $\mathrm{Q}_{\mathrm{obs} \text {,max }}$ is the maximum observed runoff, $\mathrm{Q}_{\mathrm{obs} \text {, min }}$ is the minimum observed runoff, and $\mathrm{n}$ is the number of runoff data.

A Taylor diagram was used herein to comparatively elaborate and evaluate the efficacy among the developed models. This diagram can simultaneously show three statistic parameters, i.e., correlation, root mean square error, and standard deviation.

\section{Results and discussion}

This section presents our finding as follows: (1) calibrating and validating the GR2M Model and its fitted values, (2) the suitable group of independent variables for determining two GR2M parameters using regression-based methods, (3) model performance comparison in estimating the regional GR2M model parameters, and (4) evaluation of the regionalized parameters applied in the GR2M model. The details information is delineated as follows.

Calibrating and validating the GR2M Model and its fitted values. The calibrating and validating results of the GR2M model is depicted as box plot in Fig. 5. The calibrated NSE, r, and OI values were 0.657, 0.825 , and 0.757 , respectively, and the verified NSE, $r$, and OI values were $0.449,0.743$ and 0.599 , respectively. It was a satisfactory model prediction as suggested by Lian et al. $^{51}$. The obtained $\mathrm{r}$ value of more than 0.70 showed a strong positive linear relationship between the calculated and observed runoff data ${ }^{52}$. The OI value of more than 0.60 showing the model had a relatively high accurate prediction. Figure 6 shows two examples of rainfall and runoff time series at the X.64 and X.70 stations, which were obtained from the GR2M model. The monthly rainfall time-series data is shown as a bar chart in blue. The observed and calculated runoff time-series data are shown with the line graphs in orange and green, respectively. And the solid and dot lines indicate the calibrated and validated periods, respectively. The agreement between observed and calculated runoff time-series data with a bit of underestimating the calculated runoff is found.

The statistical values of the fitted GR2M model parameters $\left(\mathrm{X}_{1}\right.$ and $\left.\mathrm{X}_{2}\right)$ for 37 runoff stations are displayed in Table 2. The production store capacity $\left(\mathrm{X}_{1}\right)$ value varies between the allowable minimum $(2.00 \mathrm{~mm})$ and maximum $(10.00 \mathrm{~mm})$ with the average and standard deviation values of $5.71 \mathrm{~mm}$ and $2.49 \mathrm{~mm}$, respectively. 


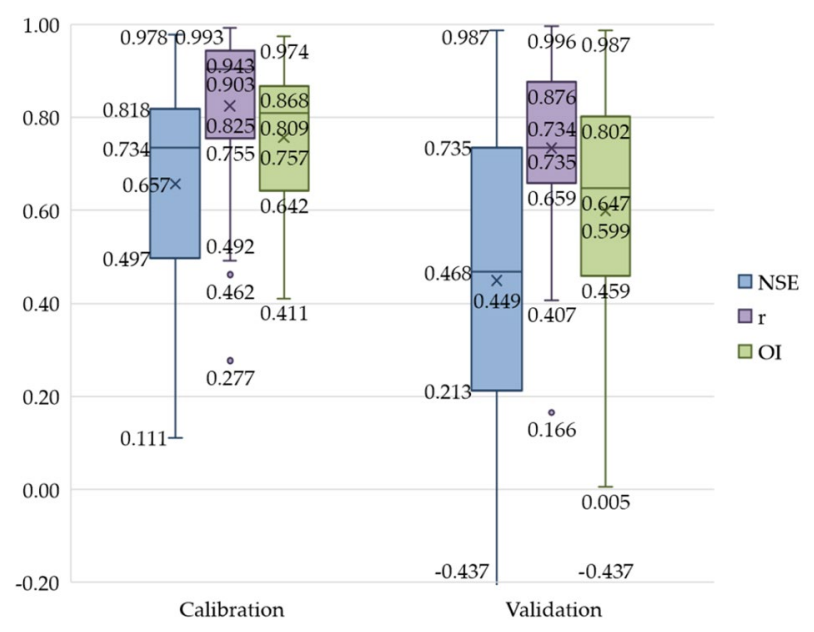

Figure 5. The results of model's calibration and validation.
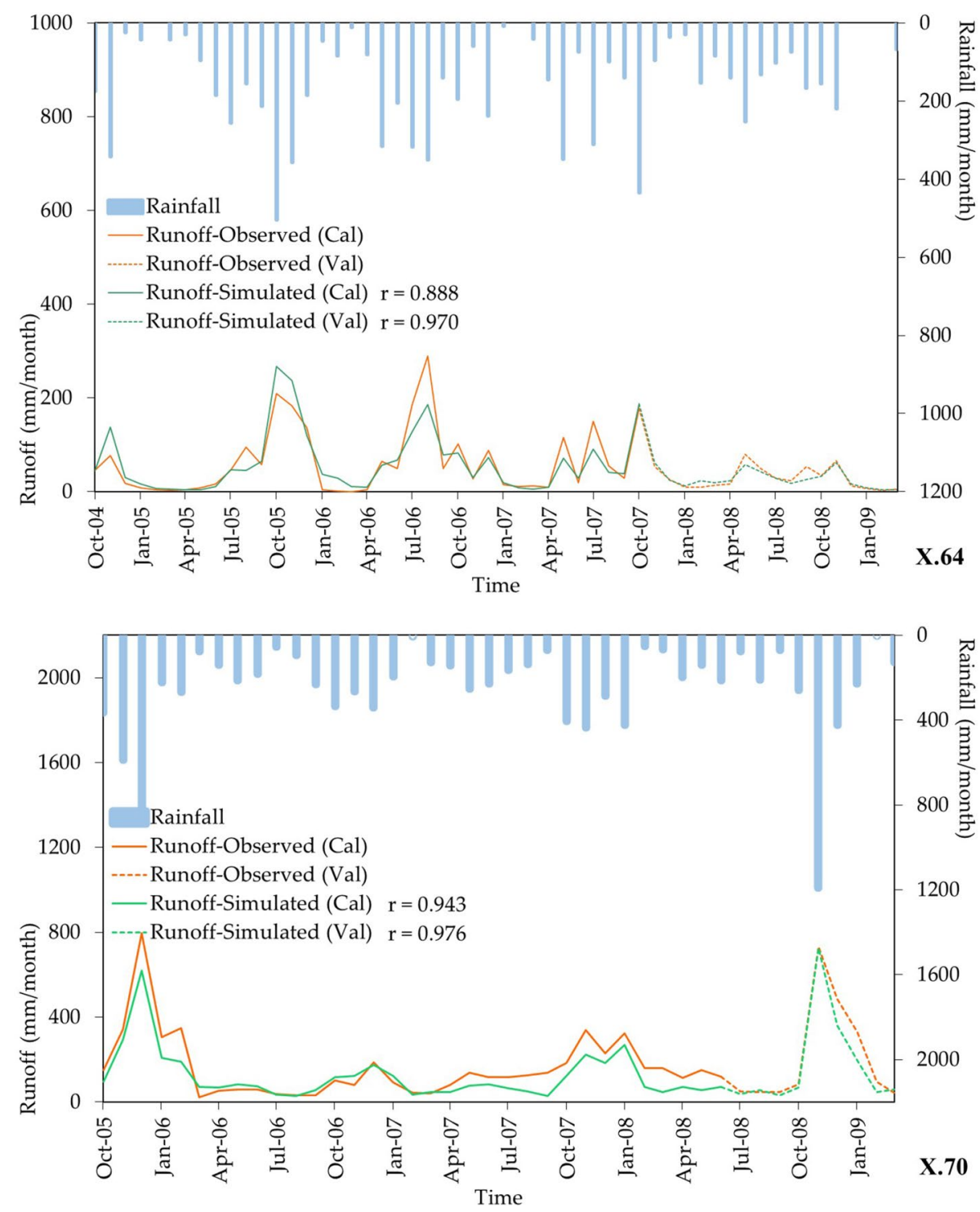

Figure 6. The rainfall and runoff time series at runoff stations X.64 and X.70. 


\begin{tabular}{|l|l|l|l|l|l|l|}
\hline Parameters & Min & Max & Avg & SD & SK & K \\
\hline $\mathrm{X}_{1}$ & $2.00 \mathrm{~mm}$ & $10.00 \mathrm{~mm}$ & $5.71 \mathrm{~mm}$ & $2.49 \mathrm{~mm}$ & -0.52 & -1.03 \\
\hline $\mathrm{X}_{2}$ & 0.54 & 1.00 & 0.93 & 0.12 & -2.01 & 3.69 \\
\hline
\end{tabular}

Table 2. The statistical values of the fitted GR2M model parameters. Remark: Min= Minimum; Max = Maximum; Avg = Average; $\mathrm{SD}=$ Standard deviation; $\mathrm{SK}=$ Skewness coefficient; and $\mathrm{K}=$ Kurtosis coefficient.

\begin{tabular}{|c|c|c|c|c|c|c|c|c|c|}
\hline \multirow[b]{2}{*}{ Methods } & \multirow[b]{2}{*}{ Scenario } & \multicolumn{4}{|l|}{$\mathrm{X}_{1}$} & \multicolumn{4}{|l|}{$\mathbf{X}_{2}$} \\
\hline & & MAE & RMSE & $\mathbf{r}$ & CA & MAE & RMSE & $\mathbf{r}$ & CA \\
\hline \multirow{3}{*}{ MLR } & 1 & 2.032 & 2.383 & 0.237 & 1.787 & 0.083 & 0.110 & 0.312 & 0.365 \\
\hline & 2 & 1.462 & 1.820 & 0.671 & 1.277 & 0.059 & 0.078 & 0.733 & 0.200 \\
\hline & 3 & 1.455 & 1.797 & 0.681 & 1.263 & 0.053 & 0.070 & 0.794 & 0.164 \\
\hline \multirow{3}{*}{$\mathrm{RF}$} & 1 & 0.658 & 0.861 & 0.963 & 0.531 & 0.036 & 0.045 & 0.971 & 0.046 \\
\hline & 2 & 0.595 & 0.790 & 0.976 & 0.478 & 0.024 & 0.036 & 0.984 & 0.031 \\
\hline & 3 & 0.580 & 0.772 & 0.974 & 0.468 & 0.028 & 0.039 & 0.983 & 0.033 \\
\hline \multirow{3}{*}{ M5 } & 1 & 2.072 & 2.453 & 0.000 & 1.842 & 0.083 & 0.109 & 0.312 & 0.365 \\
\hline & 2 & 1.226 & 1.578 & 0.790 & 1.060 & 0.051 & 0.070 & 0.799 & 0.161 \\
\hline & 3 & 1.502 & 1.917 & 0.624 & 1.343 & 0.048 & 0.065 & 0.829 & 0.142 \\
\hline
\end{tabular}

Table 3. The suitable group of independent variables for determining two GR2M parameters.

The skewness and kurtosis $\mathrm{X}_{1}$ values of -0.52 , and -1.03 , respectively, indicated that the production store capacity $\left(\mathrm{X}_{1}\right)$ in the southern river basin, Thailand, has left skew platykurtic, and non-symmetric distributions. The groundwater exchange rate $\left(\mathrm{X}_{2}\right)$ value varies between 0.54 and 1.00. Most $\mathrm{X}_{2}$ values are 1.0, which is the maximum value, resulting in its average $\mathrm{X} 2$ value of 0.93 with a meagre standard deviation value of 0.12 . The skewness and kurtosis values of $\mathrm{X}_{2}$ were -2.01 , and 3.69, respectively, indicated that the groundwater exchange rate $\left(\mathrm{X}_{2}\right)$ in the southern river basin, Thailand, has left skew, leptokurtic, and non-symmetric distributions. It can observe that the positive obtained groundwater exchange rate (X2) value. Thus, it shows no groundwater runs out of the basin.

The suitable group of independent variables for determining two GR2M parameters using regression-based methods. The results of investigating three scenarios for selecting the most suitable group of independent variables, that is, (1) scenario-1: using only the basin's physical characteristics, (2) scenario-2: using only hydrological information, and (3) scenario-3: combining those mentioned variables in scenarios 1 and 2. The results as shown in Table 3 indicates that scenario-1 received the worse performance for all cases due to giving the highest CA values than other cases. The italic number in Table 3 shows the scenario giving the best performance. For developing the regionalized $X_{1}$ and $X_{2}$ equations with MLR, we found that the most suitable group of independent variables was scenario-3. Also, the scenario-3 used for developing the regionalized $\mathrm{X}_{1}$ equation in which RF was the best independent variables. In scenario-2, the regionalized $\mathrm{X}_{2}$ equation developed by RF gave the best performance. By using the scenario-2, the regionalized $\mathrm{X}_{1}$ equation developed by $\mathrm{M} 5$ was the best. In scenario-3, the regionalized $\mathrm{X}_{2}$ equation developed by M5 gave the best performance. The explicit equations for estimating $X_{1}$ and $X_{2}$ values using MLR and M5 were shown in Eqs. (11) to (14). It should be noticed that the equation for $\mathrm{X}_{2}$ obtained from M5 method excluded variables of the basin's physical characteristics, although scenario-3 was selected the best one. RF is a machine learning algorithm and it has no an explicit equation like MLR and M5.

$M L R$.

$$
\begin{aligned}
\mathrm{X}_{1}= & 3.90 \times 10^{-5} \mathrm{~A}-1.48 \times 10^{-6} \mathrm{~L}+2.10 \times 10^{-5} \mathrm{~L}_{\mathrm{c}}-0.109 \mathrm{RF}_{2}-0.079 \mathrm{RF}_{3}-0.052 \mathrm{RF}_{4} \\
& -0.031 \mathrm{RF}_{5}-0.073 \mathrm{RF}_{6}-0.049 \mathrm{RF}_{7}-0.060 \mathrm{RF}_{8}-0.056 \mathrm{RF}_{9}-0.039 \mathrm{RF}_{10} \\
& -0.067 \mathrm{RF}_{11}-0.055 \mathrm{RF}_{12}+0.053 \mathrm{RF}_{\mathrm{y}}+7.671
\end{aligned}
$$




\begin{tabular}{|l|l|l|l|l|l|l|l|l|l|c|}
\hline \multirow{2}{*}{ Statistical indices } & \multicolumn{10}{l|}{$\mathbf{X}_{\mathbf{1}}$} \\
\cline { 2 - 13 } & MLR & RF & M5 & SPA & PSA & MLR & RF & M5 & SPA & PSA \\
\hline MAE & 1.45 & 0.58 & 1.50 & 1.67 & 1.95 & 0.05 & 0.03 & 0.05 & 0.08 & 0.10 \\
\hline RMSE & 1.80 & 0.77 & 1.92 & 2.41 & 2.46 & 0.07 & 0.04 & 0.07 & 0.12 & 0.14 \\
\hline r & 0.68 & 0.97 & 0.62 & 0.39 & 0.30 & 0.79 & 0.98 & 0.83 & 0.27 & -0.16 \\
\hline CA & 1.26 & 0.47 & 1.34 & 1.64 & 1.77 & 0.16 & 0.03 & 0.14 & 0.37 & 0.41 \\
\hline
\end{tabular}

Table 4. Statistical indices for estimating $X_{1}$ and $X_{2}$ values.

$$
\begin{aligned}
\mathrm{X}_{2}= & 3.57 \times 10^{-5} \mathrm{~A}-1.54 \times 10^{-6} \mathrm{~L}+2.59 \times 10^{-7} \mathrm{~L}_{\mathrm{c}}-6.92 \times 10^{-4} \mathrm{RF}_{2}-2.07 \times 10^{-3} \mathrm{RF}_{3} \\
& -5.38 \times 10^{-4} \mathrm{RF}_{4}-1.56 \times 10^{-4} \mathrm{RF}_{5}-5.29 \times 10^{-4} \mathrm{RF}_{6}-1.19 \times 10^{-3} \mathrm{RF}_{7} \\
& -1.24 \times 10^{-3} \mathrm{RF}_{8}-1.23 \times 10^{-3} \mathrm{RF}_{9}-5.90 \times 10^{-4} \mathrm{RF}_{10}-1.68 \times 10^{-3} \mathrm{RF}_{11} \\
& -9.11 \times 10^{-4} \mathrm{RF}_{12}+7.74 \times 10^{-4} \mathrm{RF}_{\mathrm{y}}+1.270
\end{aligned}
$$

M5.

$$
\begin{aligned}
\mathrm{X}_{1}= & -0.022 \mathrm{RF}_{2}-0.0012 \mathrm{RF}_{3}-0.0062 \mathrm{RF}_{6}-0.0041 \mathrm{RF}_{9}+0.0019 \mathrm{RF}_{\mathrm{y}} \\
& +6.5015: \text { if } \mathrm{RF}_{6} \leq 152.345, \text { and } \mathrm{RF}_{\mathrm{y}} \leq 1701.835 \\
\mathrm{X}_{1}= & -0.0238 \mathrm{RF}_{2}-0.0013 \mathrm{RF}_{3}-0.0062 \mathrm{RF}_{6}-0.0016 \mathrm{RF}_{7}-0.0041 \mathrm{RF} \mathrm{F}_{9} \\
& +0.0019 \mathrm{RF}_{\mathrm{y}}+6.9793: \text { if } \mathrm{RF}_{6} \leq 152.345, \text { and } \mathrm{RF}_{\mathrm{y}}>1701.835 \\
\mathrm{X}_{1}= & -0.0549 \mathrm{RF}_{2}-0.0178 \mathrm{RF}_{3}-0.0048 \mathrm{RF}_{6}-0.0018 \mathrm{RF}_{9}-0.0065 \mathrm{RF}_{11}+0.0015 \mathrm{RF}_{\mathrm{y}} \\
& +7.1315: \text { if } \mathrm{RF}_{6}>152.345, \mathrm{RF}_{3} \leq 125.635, \text { and } \mathrm{RF}_{2} \leq 36.805 \\
\mathrm{X}_{1}= & -0.057 \mathrm{RF}_{2}-0.0178 \mathrm{RF}_{3}-0.0048 \mathrm{RF}_{6}-0.0017 \mathrm{RF}_{9}-0.0071 \mathrm{RF}_{11}+0.0015 \mathrm{RF}_{\mathrm{y}} \\
& +6.6992: \text { if } \mathrm{RF}_{6}>152.345, \mathrm{RF}_{3} \leq 125.635, \text { and } \mathrm{RF}_{2}>36.805 \\
\mathrm{X}_{1}= & -0.0368 \mathrm{RF}_{2}-0.0213 \mathrm{RF}_{3}-0.0048 \mathrm{RF}_{6}-0.0032 \mathrm{RF}_{9}+0.0015 \mathrm{RF}_{\mathrm{y}} \\
& +7.2107: \text { if } \mathrm{RF}_{6}>152.345, \mathrm{and}_{\mathrm{RF}}>125.635 \\
& \mathrm{X}_{2}=-0.0003 \mathrm{RF}_{8}-0.0002 \mathrm{RF}_{11}+1.0979: \mathrm{if}_{\mathrm{RF}} \leq 105.745 \\
& \mathrm{X}_{2}=0.0006 \mathrm{RF}_{6}-0.0002 \mathrm{RF}_{8}-0.0007 \mathrm{RF}_{11}+0.0003 \mathrm{RF}_{12}-0.0002 \mathrm{RF}_{\mathrm{y}} \\
& +1.2801: \text { if } \mathrm{RF}_{8}>105.745
\end{aligned}
$$

where $\mathrm{A}=$ basin area, $\mathrm{L}=$ river length, $\mathrm{L}_{\mathrm{c}}=$ river length from the basin's centroid to the basin outlet, $\mathrm{RF}_{1}, \mathrm{RF}_{2}$, $\mathrm{RF}_{3}, \ldots$, and $\mathrm{RF}_{12}=$ average monthly rainfall in January, February, March, ..., and December, respectively, and $\mathrm{RF}_{\mathrm{y}}=$ average annual rainfall.

Model performance comparison in estimating the regional GR2M model parameters. In this section, the application of five methods (i.e., MLR, RF, M5, SPA, and PSA) were applied for developing the regionalized GR2M parameters, which are presented and discussed. The first three methods are based on the regression-based method and the rest two methods are distance-based method. Comparison of the fitted $\mathrm{X}_{1}$ and $\mathrm{X}_{2}$ parameters in the GR2M model and the two parameters obtained from those five methods was conducted. The results of applying those five methods to estimate $\mathrm{X}_{1}$ and $\mathrm{X}_{2}$ values are summarized in Table 4 for all 37 runoff stations. It indicated RF gave the best performance for estimating $\mathrm{X}_{1}$ due to providing the lowest CA value, following by MLR, M5, SPA, and PSA, respectively. Likewise, RF gave the best performance for estimating $\mathrm{X}_{2}$, followed by M5, MLR, SPA, and PSA.

Evaluation of the regionalized parameters applied in the GR2M model. This section aims to present the performance evaluation of the regionalized GR2M parameters developed in the previous section. Those parameters, areal monthly rainfall and evapotranspiration were used as input parameters for the GR2M model. With the same input data sets of areal monthly rainfall, evapotranspiration and different $\mathrm{X}_{1}$ and $\mathrm{X}_{2}$ values obtained from five different methods, we got five monthly runoff time-series as the GR2M model's output data. Those monthly runoff time-series were compared to that of the calibrated and validated GR2M model. Figure 7 shows the box plot graph, which was obtained from evaluating the GR2M model's effectiveness by using the regionalized GR2M parameters. Also, Table 5 presents the comparison of efficiency criteria obtained from 
Calibration

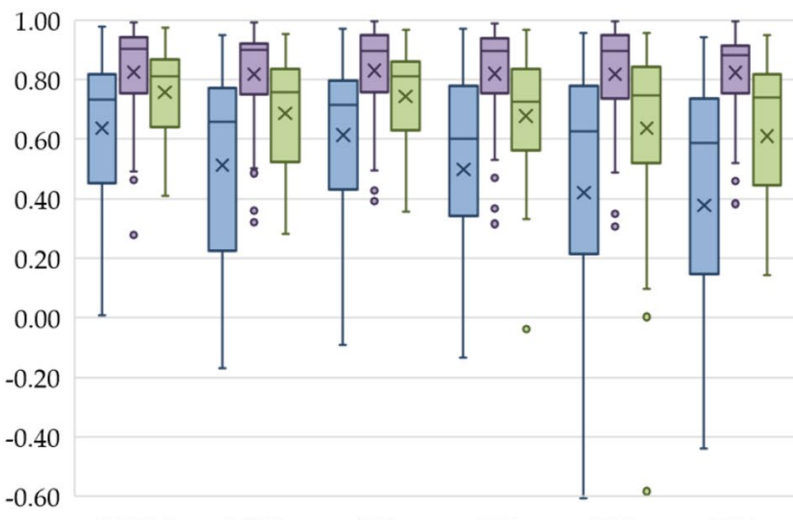

Validation

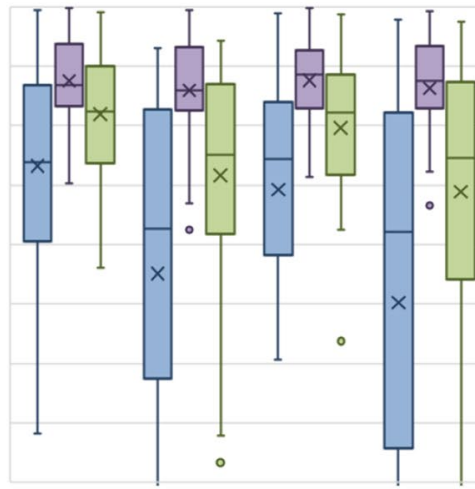

GR2M MLR RF

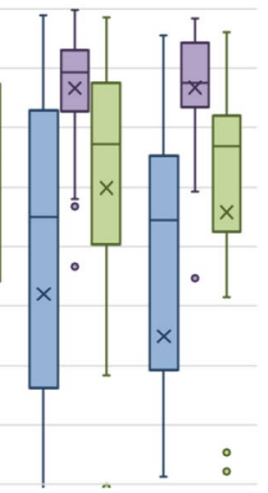

M5 $\square$ NSE

$\square \mathrm{r}$

$\square \mathrm{OI}$

Figure 7. Comparative results of applying the estimated $\mathrm{X} 1$ and $\mathrm{X} 2$ values with five methods in the GR2M model.

\begin{tabular}{|c|c|c|c|c|c|c|}
\hline \multirow[b]{3}{*}{ Method } & \multicolumn{6}{|c|}{ Efficiency criteria } \\
\hline & \multicolumn{3}{|c|}{ Calibration } & \multicolumn{3}{|c|}{ Validation } \\
\hline & NSE & $\mathbf{r}$ & OI & NSE & $\mathbf{r}$ & OI \\
\hline \multicolumn{7}{|l|}{ GR2M } \\
\hline MAX & 0.978 & 0.993 & 0.974 & 0.987 & 0.996 & 0.980 \\
\hline MIN & 0.007 & 0.277 & 0.411 & -0.437 & 0.407 & 0.120 \\
\hline Avg & 0.637 & 0.825 & 0.757 & 0.465 & 0.750 & 0.639 \\
\hline SD & 0.256 & 0.170 & 0.153 & 0.354 & 0.166 & 0.213 \\
\hline \multicolumn{7}{|l|}{ MLR } \\
\hline MAX & 0.950 & 0.991 & 0.954 & 0.860 & 0.987 & 0.886 \\
\hline MIN & -0.170 & 0.320 & 0.280 & -1.906 & 0.249 & -0.628 \\
\hline Avg & 0.513 & 0.817 & 0.686 & 0.102 & 0.719 & 0.433 \\
\hline SD & 0.325 & 0.171 & 0.188 & 0.713 & 0.188 & 0.399 \\
\hline \multicolumn{7}{|l|}{ RF } \\
\hline MAX & 0.970 & 0.995 & 0.968 & 0.979 & 0.995 & 0.972 \\
\hline MIN & -0.091 & 0.393 & 0.357 & -0.881 & 0.428 & -0.125 \\
\hline Avg & 0.613 & 0.830 & 0.744 & 0.384 & 0.752 & 0.592 \\
\hline SD & 0.275 & 0.164 & 0.164 & 0.442 & 0.162 & 0.260 \\
\hline \multicolumn{7}{|l|}{ M5 } \\
\hline MAX & 0.970 & 0.990 & 0.968 & 0.955 & 0.986 & 0.948 \\
\hline MIN & -0.748 & 0.315 & -0.039 & -2.235 & 0.235 & -0.804 \\
\hline Avg & 0.497 & 0.820 & 0.678 & 0.004 & 0.726 & 0.378 \\
\hline SD & 0.369 & 0.172 & 0.211 & 0.806 & 0.196 & 0.448 \\
\hline \multicolumn{7}{|l|}{ SPA } \\
\hline MAX & 0.955 & 0.994 & 0.958 & 0.977 & 0.995 & 0.970 \\
\hline MIN & -1.819 & 0.307 & -0.583 & -3.379 & 0.133 & -1.534 \\
\hline Avg & 0.420 & 0.818 & 0.636 & 0.041 & 0.733 & 0.398 \\
\hline SD & 0.580 & 0.179 & 0.323 & 0.902 & 0.194 & 0.512 \\
\hline \multicolumn{7}{|l|}{ PSA } \\
\hline MAX & 0.941 & 0.994 & 0.948 & 0.909 & 0.967 & 0.920 \\
\hline MIN & -2.084 & 0.383 & -0.724 & -3.459 & 0.094 & -1.577 \\
\hline Avg & 0.377 & 0.822 & 0.609 & -0.102 & 0.735 & 0.316 \\
\hline SD & 0.567 & 0.156 & 0.320 & 1.035 & 0.194 & 0.577 \\
\hline
\end{tabular}

Table 5. The performance comparison of applying the estimated $X_{1}$ and $X_{2}$ values in the GR2M model with 6 methods. Remark: $\mathrm{MAX}=$ Maximum; $\mathrm{MIN}=$ Minimum; Avg = Average; $\mathrm{SD}=$ Standard deviation. 


\begin{tabular}{|l|c|c|c|c|c|}
\hline \multirow{2}{*}{ Range } & \multicolumn{5}{|l|}{$\begin{array}{l}\text { Regionalization methods } \\
\text { (station) }\end{array}$} \\
\cline { 2 - 6 } & MLR & RF & M5 & SPA & PSA \\
\hline $0.7 \leq$ NSE & 9 & 13 & 8 & 10 & 2 \\
\hline $0.5 \leq$ NSE $<0.7$ & 5 & 7 & 7 & 8 & 12 \\
\hline $0.3 \leq \mathrm{NSE}<0.5$ & 10 & 9 & 8 & 5 & 7 \\
\hline NSE $<0.3$ & 13 & 8 & 14 & 14 & 16 \\
\hline $0.7 \leq \mathrm{r}$ & 24 & 27 & 26 & 27 & 27 \\
\hline $0.5 \leq \mathrm{r}<0.7$ & 10 & 9 & 9 & 6 & 8 \\
\hline $0.3 \leq \mathrm{r}<0.5$ & 3 & 1 & 2 & 4 & 1 \\
\hline $\mathrm{r}<0.3$ & 0 & 0 & 0 & 0 & 1 \\
\hline $0.7 \mathrm{OI}$ & 13 & 20 & 15 & 16 & 13 \\
\hline $0.5 \mathrm{OI}<0.7$ & 13 & 10 & 9 & 9 & 9 \\
\hline $0.3 \mathrm{OI}<0.5$ & 5 & 6 & 5 & 5 & 7 \\
\hline $\mathrm{OI}<0.3$ & 6 & 1 & 8 & 7 & 8 \\
\hline
\end{tabular}

Table 6. The performance criteria of the analysis method for estimating parameters.

applying $\mathrm{X}_{1}$ and $\mathrm{X}_{2}$ values in the GR2M model with five regionalized methods. As usual, the calibrated model's performance for all methods was better than those of the validated ones. Figure 7 and Table 5 show that the average values of NSE, $r$, and OI obtained from the calibration stage gave better values than those obtained from the validation stage. In addition, RF gave the best results when considering NSE and OI values for both calibration and validation stages. Table 6 shows the number of runoff stations that were categorized into four groups with the same interval for each statistical index. By this way, we can see and compare the five methods' effectiveness in our experiment easily. Considering NSE, $r$, and OI values of equal or more than 0.70 simultaneously, we found that RF gave the best performance in monthly runoff estimation due to providing the highest total number of runoff stations of 60 (i.e., NSE, r, and OI values are equal or more than 0.70 simultaneously in those 60 stations), followed by SPA (53 stations), M5 (49 stations), MLR (46 stations), and PSA (42 stations). Figure 8 presents the scatter plot of three examples of X.44, X.67A, and X.234 runoff station. The graph shows the relationship between the observed and the simulated runoff obtained from GR2M model, MLR, RF, M5, SPA, and PSA in both calibration and validation stages. The perfect line is depicted as the 45 -degree diagonal solid line.

Figure 9 presents a Taylor diagram that compares among five regionalized GR2M model and the calibrated and validated GR2M model. As shown in Fig. 9, all models gave a standard deviation value less than that of the observed runoff time series, except for PSA. RF provided the results closest to GR2M's results, followed by SPA, M5, PSA, and MLP. However, in case of lack of basin's physical characteristics and hydrological data, it would recommend using SPA since it only needs information on the distance between a gauged station (or donor station) and ungauged stations (or a target station).

\section{Conclusion}

The performance investigation of the regionalized GR2M model parameters for estimating monthly runoff in the ungauged basin was conducted in this research work. We selected 37 runoff gauged stations located in the southern basin, Thailand, as the study case. The regression-based and distance-based methods were applied for this purpose. Using regression-based methods to determine two GR2M parameters, the hydrological data was more suitable group of independent variables than the basin's physical characteristics. We also found that RF gave the best performance for estimating $\mathrm{X}_{1}$ and $\mathrm{X}_{2}$ values due to providing the lowest error, followed by $\mathrm{M} 5$, MLR, SPA, and PSA. However, by simultaneously considering NSE, $r$, and OI values, RF provided the best performance in estimating monthly runoff time series by giving NSE, $r$, and OI values of equal or more than 0.70 , followed by SPA, M5, MLR, and PSA. Furthermore, by using a Taylor diagram, we found that RF provided the results closest to GR2M's results, followed by SPA, M5, PSA, and MLP. However, in case of lack of basin's physical characteristics and hydrological information, it would recommend using SPA since it only needs information on the distance between a gauged station (or donor station) and ungauged stations (or a target station). Estimating monthly runoff time series in the ungauged basin via the regionalization methods could be drastically useful for water resources planning and management. 



Figure 8. The relationship between the observed runoff and simulated runoff obtained from six methods in X.44, X.67, and X.234. 

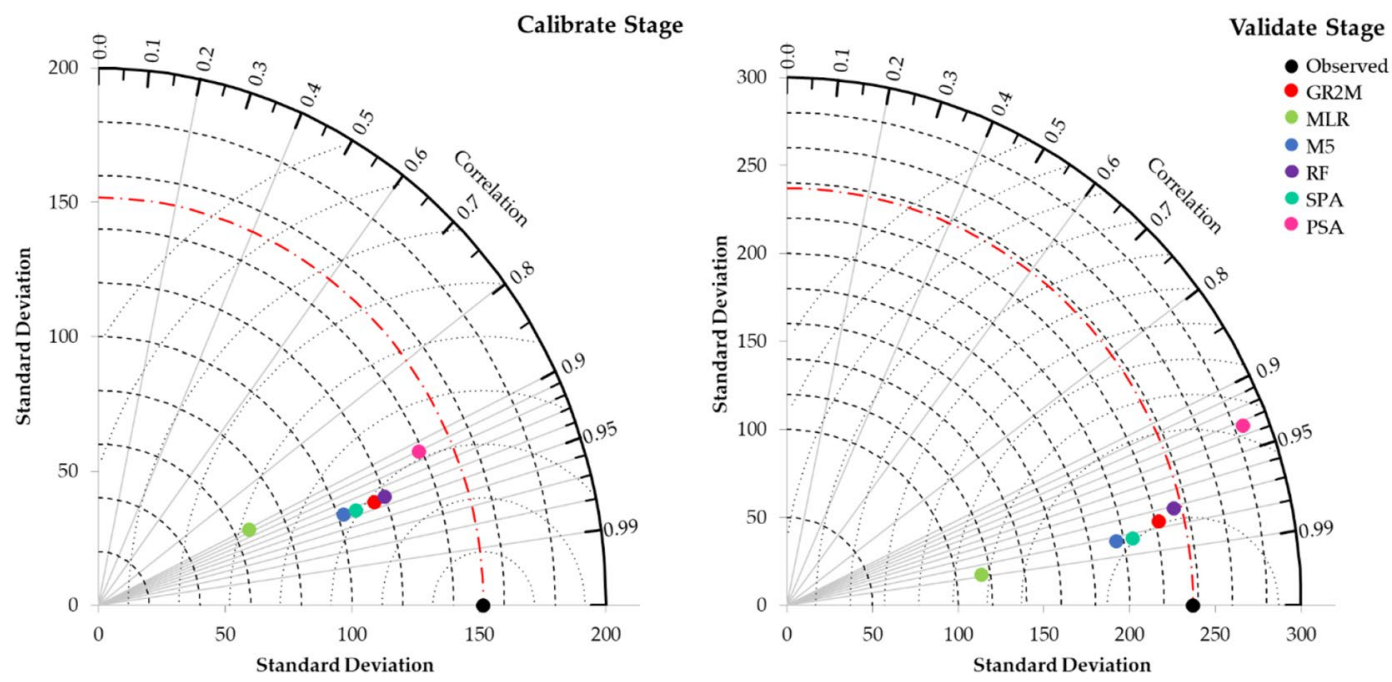

Figure 9. Taylor diagram for the regionalized GR2M model for training and testing stages.

Received: 21 March 2021; Accepted: 14 September 2021

Published online: 07 October 2021

\section{References}

1. Athira, P., Sudheer, K., Cibin, R. \& Chaubey, I. Predictions in ungauged basins: an approach for regionalization of hydrological models considering the probability distribution of model parameters. Stoch. Environ. Res. Risk Assess. 30, 1131-1149 (2016).

2. Razavi, T. \& Coulibaly, P. Streamflow prediction in ungauged basins: Review of regionalization methods. J. Hydrol. Eng. 18, 958-975 (2013).

3. Swain, J. B. \& Patra, K. C. Streamflow estimation in ungauged catchments using regionalization techniques. J. Hydrol. 554, 420-433 (2017).

4. Chaibou Begou, J. et al. Multi-site validation of the SWAT model on the Bani catchment: Model performance and predictive uncertainty. Water Resour. Manag. 8, 178 (2016).

5. Heng, S. \& Suetsugi, T. Comparison of regionalization approaches in parameterizing sediment rating curve in ungauged catchments for subsequent instantaneous sediment yield prediction. J. Hydrol. 512, 240-253 (2014).

6. Piman, T. \& Babel, M. Prediction of rainfall-runoff in an ungauged basin: Case study in the mountainous region of Northern Thailand. J. Hydrol. Eng. 18, 285-296 (2013).

7. Yang, X., Magnusson, J., Rizzi, J. \& Xu, C.-Y. Runoff prediction in ungauged catchments in Norway: Comparison of regionalization approaches. Hydrol. Res. 49, 487-505 (2018).

8. Bao, Z. et al. Comparison of regionalization approaches based on regression and similarity for predictions in ungauged catchments under multiple hydro-climatic conditions. J. Hydrol. 466, 37-46 (2012).

9. Kanishka, G. \& Eldho, T. Streamflow estimation in ungauged basins using watershed classification and regionalization techniques. J. Earth Syst. Sci. 129, 1-18 (2020).

10. Arsenault, R., Breton-Dufour, M., Poulin, A., Dallaire, G. \& Romero-Lopez, R. Streamflow prediction in ungauged basins: analysis of regionalization methods in a hydrologically heterogeneous region of Mexico. Hydrol. Sci. J. 64, 1297-1311 (2019).

11. Akay, H., Koçyiğit, M. B. \& Yanmaz, A. M. Effect of using multiple stream gauging stations on calibration of hydrologic parameters and estimation of hydrograph of ungauged neighboring basin. Arab. J. Geosci. 11, 1-11 (2018).

12. Tegegne, G. \& Kim, Y.-O. Modelling ungauged catchments using the catchment runoff response similarity. J. Hydrol. 564, 452-466 (2018).

13. Koçyiğit, M. B., Akay, H. \& Yanmaz, A. M. Effect of watershed partitioning on hydrologic parameters and estimation of hydrograph of an ungauged basin: a case study in Gokirmak and Kocanaz, Turkey. Arab. J. Geosci. 10, 1-13 (2017).

14. Hussain, D. \& Khan, A. A. Machine learning techniques for monthly river flow forecasting of Hunza River, Pakistan. Earth Sci. Inform. 13, 939-949 (2020).

15. Schoppa, L., Disse, M. \& Bachmair, S. Evaluating the performance of random forest for large-scale flood discharge simulation. J. Hydrol. 590, 125531 (2020).

16. Wang, Q. \& Wang, S. J. W. Machine learning-based water level prediction in Lake Erie. Water 12, 2654 (2020).

17. Araza, A., Hein, L., Duku, C., Rawlins, M. A. \& Lomboy, R. J. B. Data-driven streamflow modelling in ungauged basins: regionalizing random forest (RF) models. Preprint at biorxiv.org (2020).

18. Saadi, M., Oudin, L. \& Ribstein, P. J. W. Random forest ability in regionalizing hourly hydrological model parameters. Water 11, 1540 (2019).

19. Dezetter, A. et al. Simulation of runoff in West Africa: Is there a single data-model combination that produces the best simulation results?. J. Hydrol. 354, 203-212 (2008).

20. Okkan, U. \& Fistikoglu, O. Evaluating climate change effects on runoff by statistical downscaling and hydrological model GR2M. Theor. Appl. Climatol. 117, 343-361 (2014).

21. Lyon, S. W., King, K., Polpanich, O.-U. \& Lacombe, G. Assessing hydrologic changes across the Lower Mekong Basin. J. Hydrol. Reg. Stud. 12, 303-314 (2017).

22. Boulariah, O., Longobardi, A. \& Meddi, M. in 15th International Conference on Environment Science and Technology, CEST2017 (00694). 1-4

23. Topalović, Ž, Todorović, A. \& Plavšić, J. Evaluating the transferability of monthly water balance models under changing climate conditions. Hydrol. Sci. J. 65, 928-950 (2020).

24. Hadour, A., Mahé, G. \& Meddi, M. Watershed based hydrological evolution under climate change effect: An example from North Western Algeria. J. Hydrol. Reg. Stud. 28, 100671 (2020).

25. Rintis, H. \& Setyoasri, Y. P. in Applied Mechanics and Materials. 24-29 (Trans Tech Publ). 
26. O'Connor, P., Murphy, C., Matthews, T. \& Wilby, R. L. Reconstructed monthly river flows for Irish catchments 1766-2016. Geosci. Data J. 8, 34-54 (2020).

27. Zamoum, S. \& Souag-Gamane, D. Monthly streamflow estimation in ungauged catchments of northern Algeria using regionalization of conceptual model parameters. Arab. J. Geosci. 12, 1-14 (2019).

28. Vaze, J. et al. Rainfall-runoff modelling across southeast Australia: Datasets, models and results. Aust. J. Water Resour. 14, 101-116 (2011).

29. Peña-Arancibia, J. L., Stewart, J. P. \& Kirby, J. M. Water balance trends in irrigated canal commands and its implications for sustainable water management in Pakistan: Evidence from 1981 to 2012. Agric. Water Manag. 245, 106648 (2020).

30. López-Lambraño, A. A. et al. Supply and demand analysis of water resources. Case study: Irrigation water demand in a semi-arid zone in Mexico. Agriculture 10, 333 (2020).

31. Zhang, X. et al. Optimal irrigation water allocation in Hetao Irrigation District considering decision makers' preference under uncertainties. Agric. Water Manag. 246, 106670 (2021).

32. Kabouya, M. Modélisation pluie-débit aux pas de temps mensuel et annuel en Algérie septentrionale (Université Paris Sud Orsay, 1990).

33. Makhlouf, Z. \& Michel, C. A two-parameter monthly water balance model for French watersheds. J. Hydrol. 162, 299-318 (1994).

34. Mouelhi, S. Vers une chaine cohérente de modèles pluie-débit conceptuels globaux aux pas de temps pluriannuel, annuel, mensuel et journalier, Doctorat Géosciences et ressources naturelles, ENGREF Paris, (2003).

35. Mouelhi, S., Michel, C., Perrin, C. \& Andréassian, V. Stepwise development of a two-parameter monthly water balance model. J. Hydrol. 318, 200-214 (2006).

36. Nounangnonhou, T., Fifatin, F., Lokonon, B., Acakpovi, A. \& Sanya, E. Modelling and Prediction of Ouémé (Bénin) River Flows by 2040 Based on GR2M Approach. LARHYSS Journal P-ISSN-1112-3680/E-ISSN-2602-7828, 71-91 (2018).

37. Fathi, M. M., Awadallah, A. G., Abdelbaki, A. M. \& Haggag, M. A new Budyko framework extension using time series SARIMAX model. J. Hydrol. 570, 827-838 (2019).

38. Bachir, S., Nouar, B., Hicham, C., Azzedine, H. \& Larbi, D. Application of GR2M for rainfall-runoff modeling in Kébir Rhumel Watershed, North East of Algeria. World Appl. Sci. J. 33, 1623-1630 (2015).

39. Rwasoka, D., Madamombe, C., Gumindoga, W. \& Kabobah, A. Calibration, validation, parameter indentifiability and uncertainty analysis of a 2-parameter parsimonious monthly rainfall-runoff model in two catchments in Zimbabwe. Phys. Chem. Earth Parts $A / B / C$ 67, 36-46 (2014).

40. Thornthwaite, C. W. An approach toward a rational classification of climate. Geogr. Rev. 38, 55-94 (1948).

41. Samuel, J., Coulibaly, P. \& Metcalfe, R. A. Estimation of continuous streamflow in Ontario ungauged basins: Comparison of regionalization methods. J. Hydrol. Eng. 16, 447-459 (2011).

42. Breiman, L. Random forests. Mach. Learn. 45, 5-32 (2001).

43. Breiman, L. Random Forests-Random Feature (Statistics Department, University of California, 1999).

44. Quinlan, J. R. in 5th Australian Joint Conference on Artificial Intelligence 343-348 (World Scientific).

45. Breiman, L., Friedman, J.H., Olshen, R.A., \& Stone, C.J. Classification And Regression Trees (1st edn.). (Routledge, 1984).

46. Heřmanovský, M., Havlíček, V., Hanel, M. \& Pech, P. Regionalization of runoff models derived by genetic programming. J. Hydrol. 547, 544-556 (2017).

47. Eray, O., Mert, C. \& Kisi, O. Comparison of multi-gene genetic programming and dynamic evolving neural-fuzzy inference system in modeling pan evaporation. Hydrol. Res. 49, 1221-1233 (2018).

48. Zolfaghari, M., Mahdavi, M., Rezaei, A. \& Salajegheh, A. Evaluating GR2M model in some small watersheds of Iran (Case study Gilan and Mazandaran Provinces). J. Basic Appl. Sci. Res. 3, 463-472 (2013).

49. Kimmany, B. Effectiveness of Hydrologic Models for Streamflow Prediction in the Nam Song River Basin (Chulalongkorn University, 2016).

50. Sarzaeim, P., Bozorg-Haddad, O., Bozorgi, A. \& Loáiciga, H. A. Runoff projection under climate change conditions with datamining methods. J. Irrig. Drain. Eng. 143, 04017026 (2017).

51. Lian, Y. et al. Coupling of hydrologic and hydraulic models for the Illinois River Basin. J. Hydrol. 344, 210-222 (2007).

52. Ratner, B. The correlation coefficient: Its values range between $+1 /-1$, or do they?. J. Target. Meas. Anal. Mark. 17, 139-142 (2009).

\section{Acknowledgements}

The authors would like to thank the Royal Irrigation Department (RID) and the Thai Meteorological Department (TMD) to support meteorological and hydrological information needed in this study. This research was partially supported by the new strategic research (P2P) project, Walailak University, Thailand.

\section{Author contributions}

Conceptualization, methodology, supervision: P.D.; data curation, formal analysis, investigation: S.P., N.S., and F.B.; writing-original draft preparation: S.P., N.S., F.B.; writing-review and editing: L.K., P.D., and Q.B.P.; proofread the text and helped in structuring the publication: P.D. and Q.B.P. All authors read and agreed to the published version of the manuscript.

\section{Competing interests}

The authors declare no competing interests.

\section{Additional information}

Correspondence and requests for materials should be addressed to P.D. or Q.B.P.

Reprints and permissions information is available at www.nature.com/reprints.

Publisher's note Springer Nature remains neutral with regard to jurisdictional claims in published maps and institutional affiliations. 
(c) (i) Open Access This article is licensed under a Creative Commons Attribution 4.0 International cc) License, which permits use, sharing, adaptation, distribution and reproduction in any medium or format, as long as you give appropriate credit to the original author(s) and the source, provide a link to the Creative Commons licence, and indicate if changes were made. The images or other third party material in this article are included in the article's Creative Commons licence, unless indicated otherwise in a credit line to the material. If material is not included in the article's Creative Commons licence and your intended use is not permitted by statutory regulation or exceeds the permitted use, you will need to obtain permission directly from the copyright holder. To view a copy of this licence, visit http://creativecommons.org/licenses/by/4.0/.

(C) The Author(s) 2021 